\title{
Quantity Distributed Anticipated Total
}

National Cancer Institute

\section{Source}

National Cancer Institute. Quantity Distributed Anticipated Total. NCI Thesaurus. Code C106326.

Anticipated quantity of items distributed. 